\title{
CLINICAL BEHAVIOR OF Streptococcus pneUmoniae MENINGOENCEPHALITIS
}

\author{
Raisa Bu-Coifiu Fanego', Alberto J. Dorta-Contreras', Bárbara Padilla-Docal', \\ Martha O' Farril-Sanchez ${ }^{2}$, Isabel Lopez-Hernandez ${ }^{2}$
}

\begin{abstract}
Objective: There was an increased number of cases of meningoencephalitis caused by Streptococcus pneumoniae, after the successful vaccination campaigns against Neisseria meningitidis and Haemophilus influenzae. This paper aims at describing the clinical characteristics, the laboratory findings, the complications, and the therapeutic management of these patients, who have been suffering from this disease since 1993 to 2006. Method: Twelve children with Streptococcus pneumoniae meningoencephalitis admitted to the pediatric hospital of San Miguel del Padron, City of Havana in this period were assessed. Results: Children under one year are the most frequently affected. Septic shock and brain edema were the most severe complications. Three patients died, implying that this disease has a serious course. Early treatment of brain edema is very important to reduce mortality. The elective drugs for treatment of these cases of Streptococcus pneumoniae meningoencephalitis were vancomycin combined with cephalosporin, cefotaxime or ceftriaxone type. Conclusion: Patients with Streptococcus pneumoniae meningoencephalitis show clinical characteristics, complications, and sequels that are different to other bacterial meningoencephalitis, meaning that they could be helpful for physicians considering the differential diagnosis of meningoencephalitis.
\end{abstract}

KEY WORDS: streptococcus pneumoniae, meningoencephalitis, treatment.

\section{Comportamiento clinico y terapéutico de la meningoencefalitis por streptococcus pneumoniae}

Resumo - Objetivo: Existe un incremento de la meningoencefalitis producida por Streptococcus pneumoniae, después de las campañas exitosas de vacunación contra Neisseria meningitidis y Haemophilus influenzae. El objetivo de este trabajo es describir las caracteristicas clinicas, los hallazgos de laboratorio, las complicaciones y el manejo terapéutico de los pacientes que sufrieron esta enfermedad desde 1993 a 2006. Método: Se estudiaron doce niños con meningoencefalitis por Streptococcus pneumoniae ingresados en el Hospital Pediátrico de San Miguel del Padrón, Ciudad de La Habana en este periodo. Resultados: Los niños menores de un año son los más frecuentemente afectados. El shock séptico y el edema cerebral las mayores complicaciones. Tres pacientes fallecieron. Esta enfermedad ha tenido un curso serio. El tratamiento temprano del edema cerebral es muy importante para reducir la mortalidad. Los medicamentos de elección para tratar la meningoencefalitis por Strepcococcus pneumoniae en los casos estudiados fueron la vancomicina combinada con cefalosporina del tipo de la cefatoxima o la ceftriaxona. Conclusion: Los pacientes con meningoencefalitis por Streptoccocus pneumoniae exhibieron características clínica, complicaciones y secuelas las cuales se diferencian de otras meningoencefalitis bacterianas. Por eso estos elementos pueden ayudar a los médicos en el diagnóstico diferencial

PALAVRAS-CLAVE: streptococcus pneumoniae, meningoencefalitis, tratamiento.

Pneumococcus causes the death of 18000 children $\times$ $10^{5}$ inhabitants annually, meaning two children per hour, and it is responsible for four important disease, otitis, pneumonia, sepsis and meningitis, three of which may be fatal'. Latin American children under five years old may suffer from pneumococcal diseases, including 1.3 million

\footnotetext{
'Central Laboratory for Cerebrospinal Fluid (LABCEL). Medical School “Dr. Miguel Enríquez" Ramón Pintó 202, Luyanó. Apartado 10049 CP 11000 Ciudad Habana, Cuba; ${ }^{2}$ Pediatric Hospital San Miguel del Padrón. Calzada de San Miguel del Padrón 1615 entre Balear y Santa Francisca. CP 11000 Ciudad Habana, Cuba.
}

Received 22 July 2009, received in final form 23 July 2009. Accepted 4 August 2009.

Dr. Alberto Juan Dorta-Contreras - Laboratorio Central de Líquido Cefalorraquídeo (LABCEL) / Facultad de Ciencias Médicas "Dr. Miguel Enríquez" Ramón Pintó 202, Luyanó / Apartado 10049 - CP 11000 Ciudad Habana - Cuba. E-mail: adorta@infomed.sld.cu 
cases of acute otitis that may lead to deafness, 330,000 pneumonia cases, 1,200 cases of pneumococcal sepsis and 3,900 pneumonia cases. Streptococcus pneumoniae causes more than 1 million of deaths in children worldwide annually, $90 \%$ of them occurring in developing countries ${ }^{2}$.

Lately, Neisseria meningitidis and Haemophilus influenzae meningoencephalitis cases have dropped drastically due to the successful vaccination campaign carried out in Cuba by the national health system. As a result, Streptococcus pneumoniae has taken the position of the previously mentioned germs ${ }^{3}$.

Streptococcus pneumoniae affects mainly children under one year of age, specially new-born infants. However both the average age and the age range for this infection are increasing ${ }^{4}$. Thus, it is necessary to produce a vaccine with the most frequent serotypes of this bacteria in Cuba.

We describe clinical characteristics, laboratory findings, complications, therapeutic management and sequels found in a group of patients affected by the disease from 1993 to 2006.

\section{METHOD}

A descriptive, transversal and prospective study was performed through direct observation of patients since the time of their first lumbar puncture.

Sick children form peripheral municipalities, comprising both urban and suburban areas, were consulted in this hospital. Patients enrolled in this study were diagnosed with Streptococcus pneumoniae meningoencephalitis, its biological agent detected at the microbiology laboratory of the pediatric hospital of San Miguel del Padrón from 1993 to 2006. Twelve children admitted with the presumptive diagnosis of bacterial meningoencephalitis were studied.

Patients were admitted in the Intensive Care Unit of the hospital. The sera and CSF samples were simultaneously collected at the moment of admission when the symptoms started. The antibiotic and symptomatic treatment was initiated immediately after, according to the clinical characteristics of each patient. Samples were divided in aliquots; subsequently they were properly labeled and kept at $-80^{\circ} \mathrm{C}$ for further use. The laboratory variables were processed, according to international standards.

Universally accepted routine methods were used for the chemical study. Cellular and differential counting of CSF was expressed according to the number of cells $\times 10^{-6} / \mathrm{L}$, and in percentage (respectively). Normal cellular counting for children was considered to be up to 20 cells $\times 10^{-6} / \mathrm{L}$. The predominance of cells does not define etiology in bacterial meningoencephalitis.

\section{Latex agglutination test}

A modified latex agglutination test was employed for the rapid detection of Streptococcus pneumoniae made by Bio Merieux (Slidex Meningite Kit). It contains sensitizing latex particles with capsular antigens of $S$. pneumoniae (83 serotypes), A and $\mathrm{C}$ serogroup of $\mathrm{N}$. meningitidis and type $\mathrm{b} H$. influenzae. The latex agglutination test is rapid and simple to perform, yielding S. pneumoniae data directly by testing of CSF. The sensibility for S. pneumoniae is $0.1-0.5(\mathrm{Jg} / \mathrm{mL})$.

Microbiological cultures and bacterial identification

Isolation of pneumococci by inoculation of CSF and blood into solid culture media is very efficient if the patients had not been previously treated before with antibiotics. It allows for determination of the presence of $S$. pneumoniae in the initial material. The appearance and the size of pneumococcal colonies depend upon the composition of the culture medium, the biological properties and the amount of S. pneumoniae and other microorganisms in the material undergoing the assessment. The identification of pneumococci is based on their cultural and morphological properties, and it is carried out by a variety of tests.

S. pneumoniae is a Gram positive capsulated cocci. Its shape is of the lanceolate type, and it measures 0.5 to $1.2 \mu \mathrm{m}$, appearing in pairs or diplococci. They are facultative anaerobics, requiring protein and hematologic supplements.

CSF and blood samples were cultured in Oxoid chocolate agar in an environment containing $8-10 \% \mathrm{CO}_{2}$. In this type of culture, the bacteria grows as non pigmented round colonies of 1-3 mm diameter. After 48 hours in the cultures, it takes an umbilical like shape due to a progressive cellular autolysis, and the colonies usually have a greenish ring. To characterize the strain of the colony, different biochemical tests were used. Bacteriolysis with bile salts was used for the phenotypic specie identification. The optoquine susceptibility also was employed by culture of blood agar, by putting an Oxoid disk with optoquine on the surface of culture in order to measure the inhibition ring. If the ring became soluble in presence of bile salts, it is a determinant that the strain is indeed S. pneumoniae.

\section{RESULTS}

The incidence of meningoencephalitis by Streptococcus pneumoniae is shown in Fig 1.

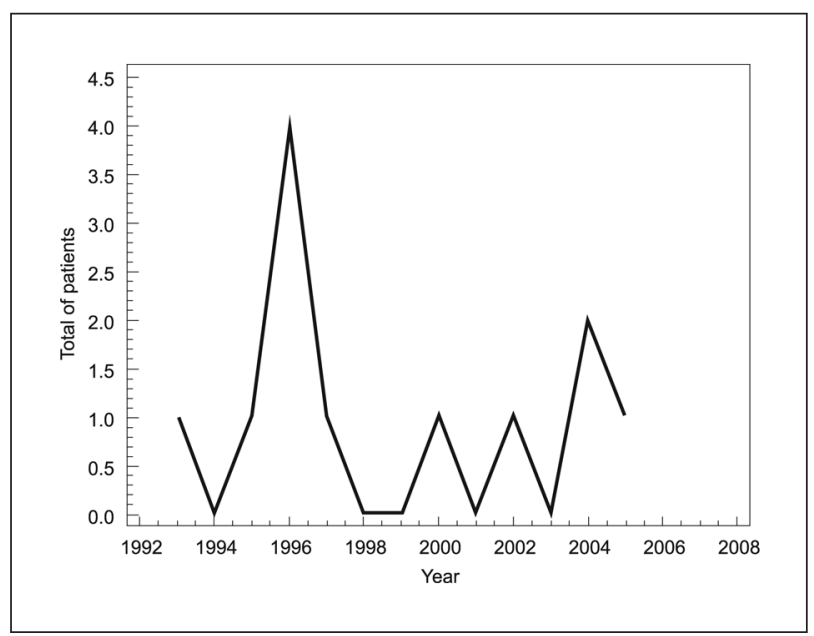

Fig 1. Incidence of S. pneumoniae meningoencephalitis. 


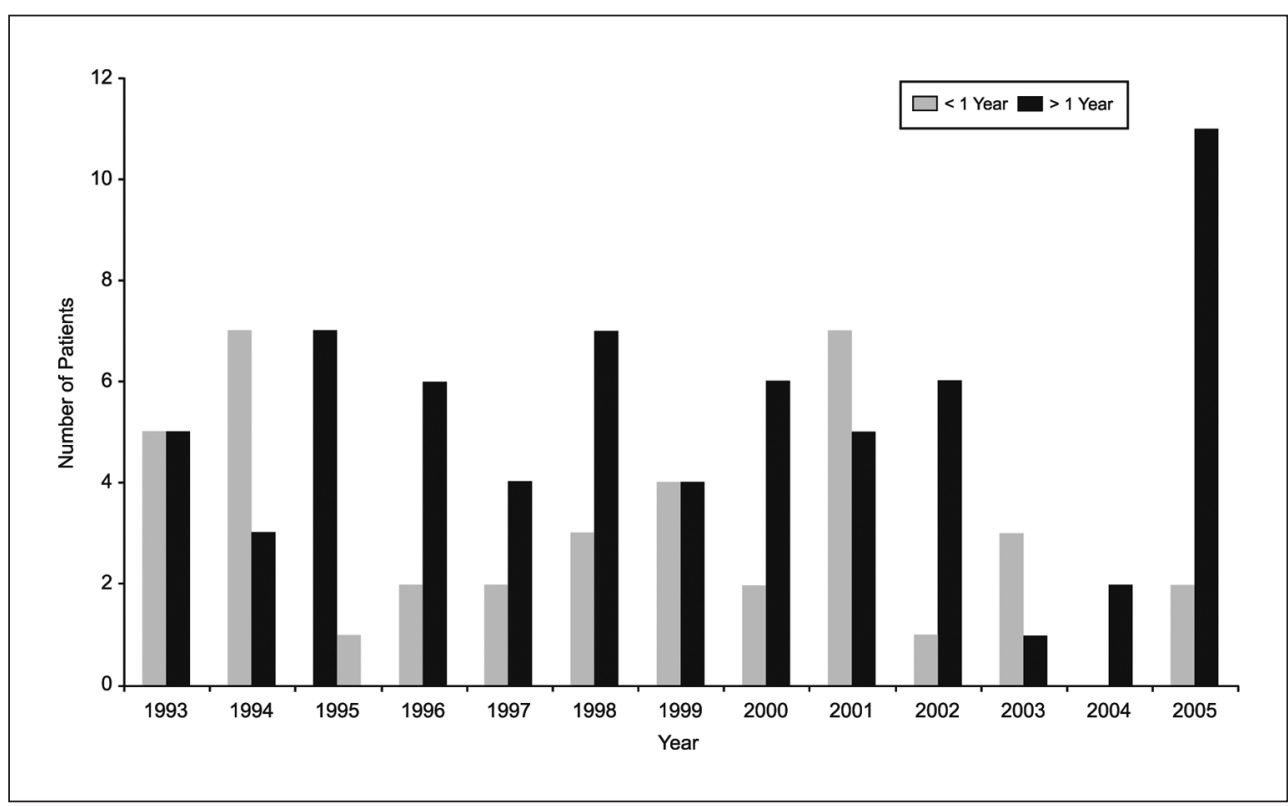

Fig 2. Incidence of unknown etiology meningoencephalitis.

Table. Streptococcus pneumoniae meningoencephalitis. Clinical and laboratory characteristics.

\begin{tabular}{|c|c|c|}
\hline \multicolumn{3}{|l|}{ Characteristics } \\
\hline Average time of incubation & \multicolumn{2}{|c|}{4.25 days } \\
\hline Range & \multicolumn{2}{|c|}{$2-6$ days } \\
\hline Symptoms and signs & No. patients & $\%$ \\
\hline ARI & 12 & 100 \\
\hline Vomiting & 5 & 41 \\
\hline Headache & 1 & 8 \\
\hline Fever & 12 & 100 \\
\hline Enlarged fontanel & 5 & 41 \\
\hline Irritability & 5 & 41 \\
\hline Somnolence & 5 & 41 \\
\hline Food rejection & 6 & 50 \\
\hline \multicolumn{3}{|l|}{ Laboratory } \\
\hline Average differential cell count CSF (\%) & \multicolumn{2}{|c|}{ Polymorphonuclear cells $=84.7$} \\
\hline diagnostic lumbar puncture & \multicolumn{2}{|c|}{ Lymphocytes=36.7 } \\
\hline Average total cells in CSF & \multicolumn{2}{|c|}{653 cells $\times 10^{-6} \mathrm{~L}$} \\
\hline CSF protein & \multicolumn{2}{|c|}{ Increased in $100 \%$ of patients } \\
\hline CSF/serum glucose Index & \multicolumn{2}{|c|}{$50 \%$ decreased of all patients } \\
\hline Average globular sedimentation rate & \multicolumn{2}{|c|}{92.7} \\
\hline \multirow[t]{2}{*}{ Average differential cell count in blood } & \multicolumn{2}{|c|}{ Polymorphonuclear cells $=65$} \\
\hline & \multicolumn{2}{|c|}{ Lymphocytes=37 } \\
\hline
\end{tabular}

The microorganism grew in all studied cases and Gram staining showed Gram-positive lanceolate diplococci.

Bacterial meningitis was suspected by cytological examination of CSF. Latex agglutination test was done directly on untreated CSF samples, showing positive reactions for S. pneumoniae

The etiology was definitively established by culture and by smear examination.
Gram-positive coccal bacteria were demonstrated in chocolate agar culture.

Morphological appearance of bacteria using optical microscopy and positive detection for biochemical tests suggested the infection with Streptococcus pneumoniae.

The high incidence of bacterial meningoencephalitis cases of non-determined cause is shown in Fig 2.

More frequent signs and symptoms are shown in Table 1. 
All patients showed brain edema and $40 \%$ had a convulsive status. Septic shock and multi organ failure affected fourth of the patients.

Computed tomography was performed in two patients, showing diffused cortical atrophy and ventriculomegaly. Cerebral edema was observed in both cases.

There were three cases of death (25\%), two of them under one year of age, the other child in the group 1-4 years.

Vancomycin was the drug of choice, in combination with cephalosporin, cefotaxime or ceftriaxone to treat Streptococcus pneumoniae meningoencephalitis in these cases.

Short-term sequels were brain paralysis in two of the 12 patients (16\%).

\section{DISCUSSION}

Low incidence of Streptococcus pneumoniae may lead to the mistaken belief that this microorganism is not a public health problem in our area. However, sometimes there is no bacterial growth due to the early treatment with antibiotics these patients, who receive these drugs when attending the primary care units. Therefore, the real number of affected patients due this bacterium may be higher ${ }^{5,6}$.

In fact, the etiological diagnosis of 106 patients was not possible, meaning that there might be a hidden incidence of Streptococcus pneumoniae that could not be verified.

Fast diagnostic methods are an alternative to improve the diagnosis since they do not need the germ to be intact, since they can recognize rests of the microorganism. For example, latex agglutination tests or polymerase chain reaction (PCR), can be used for faster diagnosis ${ }^{7}$.

All of the patients in this study had respiratory infections prior to admission. Streptococcus pneumoniae is an airborne bacterium, carrying a high spreading risk due to the little drops of $<10 \mu \mathrm{m}$ that remain suspended for more than $30 \mathrm{~min}$. These minute drops may easily reach the alveolus, carrying the risk of infection in the lung parenchyma.

Its polysaccharide capsule allows it to avoid phagocytosis, creating an invasive risk that may occur frequently in children, especially in synergy with other viral respiratory diseases. Respiratory viruses have a cytopathic effect on the cilium of the respiratory mucosa either by destroying it or altering its genetic code. The alteration of the barrier mechanisms in this situation favors the increase of Streptococcus pneumoniae previously inoculated in colonized children. Children with tubaric dysfunction or respiratory allergy are at a higher risk of suffering acute otitis media or sinusitis. Infants from developing countries are colonized earlier with higher rates of nasopharyngeal carriers. Streptococcus pneumoniae carries an extreme risk of invasive infections in immunocompromised hosts, including children with functional or surgical asplenia, AIDS or any other severe immunocompro- mised disease: diabetes, nephritis, cardiopathy or chronic respiratory syndrome ${ }^{8}$.

The main sign was fever in all cases, with weakness, food rejection or irritability. Enlarged fontanel was present in children under one year of age. Studies conducted in Spain found that $93.4 \%$ of children had fever equal to or higher than $37.5^{\circ} \mathrm{C}$ in the moment $\mathrm{o}$ admission, the mean duration was $3.25 \pm 3.71$ days (mean 2 days) and the most frequent presentation forms were hidden bacteremia $(45.6 \%)$, bacteremic pneumonia $(27.5 \%)$, meningitis (14.6\%) and bacteremic otitis (9.4\%). Bacteremic cellulitis, arthritis and mastoiditis were also present $(5.9 \%)^{9}$. Somnolence and vomits were other reported signs. There was no variation in the clinical picture of our cases in relation to those of Mexico, Brazil and Argentina ${ }^{9,10}$.

Regarding the laboratory tests, the cytochemical study showed a high number of cells in the CSF, as it was expected. This demonstrates an acute inflammatory process. Polymorphonuclear leukocytes were predominant in these patients.

All the results of the cytochemical study inferred a bacterial process in the affected children. These results match the ones found for other bacteria that affect the central nervous system. The behavioral symptoms and signs of these children were similar to those of other children abroad.

For example, in a study performed in Bogotá, Colombia, children with Streptococcus pneumoniae meningoencephalitis had similar characteristics".

The microorganism grew in all assessed cases, and Gram staining showed Gram-positive lanceolate diplococci. Gram staining method is very useful to establish a treatment for the etiological agent found. This method has a sensitivity of $60-90 \%{ }^{12}$.

One of the characteristics of the disease is that patients are in very serious condition. The main complications were brain edema, convulsive status, acid basic unbalance, septic shock and multi organ failure.

The most serious complications observed in a study conducted in the Basque Country were those related to the respiratory tract $(20.8 \%)$, pleural effusion $(7.5 \%)$, atelectasis $(2.0 \%)$ and pachypleuritis $(2.0 \%)$. Thoracoscopy were performed to two patients ${ }^{13}$.

Since brain edema was present in all patients, quantity and quality of liquids will depend on different factors: intensity of brain edema, status of the tissue perfusion, impaired capillary permeability, volemia and the existence of concomitant complications ${ }^{14}$.

The importance of using computed tomography was demonstrated. This test has diagnostic relevance where there is a correlation between the findings and the symptoms, and at the same time it has prognostic importance taking into account that some damages correlate with the 
sequels. Therefore, its use is recommended to detect intracranial complications ${ }^{15}$.

When the presence of infarction or paralysis of the cranial nerves, as well as hydrocephaly was detected by ultrasound or any other imaging technique at the moment of admission, sequels are usually expected. This may help identifying children that might need further follow-up and rehabilitation.

We considered that there is a high lethality, due to the outcome of $25 \%$ deaths.

According to a report of the Pan-American Health Organization (PAHO) in 1999, 72,000 children under 5 years of age had died due to acute respiratory infections (ARI) in Latin America, $80 \%$ of them due to pneumonia, $50 \%$ of which were caused by Streptococcus pneumoniae, on the bases on previous data. This means that 29,000 children might have died due to Streptococcus pneumoniae ${ }^{16}$.

A total of 800 children died of ARI in Argentina, according to reports of the Ministry Of health; but this number might be higher considering sub registry of cases and home deaths, which are common in all countries ${ }^{17}$.

The World Health Organization (WHO) and PAHO consider the following as risk factors: overcrowding, deficit of specific vaccines, lack of breastfeeding, low weight at birth, malnutrition, barriers to access medical care and, in some regions, deficit of vitamin $A^{18}$.

In Cuba there are no barriers to access medical care, pediatric hospitals are always ready to admit children when there is suspicion or sign of meningoencephalitis.

In general, the treatment to these patients comprised clinical support, mechanic ventilation, correction of the acid basic unbalance, of the brain edema and of the convulsions. Antibiotics were also used.

The use of inotropics was very important for the hemodynamic stabilization of the patients and they were indicated when the volume provided suggested an adequate volemia, despite of the vasodilatation they produce ${ }^{19}$.

Streptococcus pneumonia resistant-strains due to the use of antibiotics have been reported worldwide and they make the treatment difficult, leading to the increase mortality in many places ${ }^{20}$.

Some aspects should be taken into account when selecting an antibiotic to treat meningitis caused by Streptococcus pneumoniae: (1) The management of an infection in a system with low phagocytosis against a high inoculum $\left(>10^{6}\right)$. (2) A bactericide drug with good penetration through the meninges should be selected. (3) Special importance should be given to the time the drug remains in the CSF at a concentration superior to 10 times of the minimum bactericide concentration for the causative agent.

The latter is achieved with third generation cephalosporin (cefotaxime and ceftriaxone) at high doses. Penicillin-resistant Pneumococcus is increasing worldwide.
Sometimes this Pneumococcus resistance is multiple, and includes other antibiotics like tetracycline, trimethoprim sulfamethoxazole, and chloramphenicol. These infections are more frequently found in the serotypes affecting children ${ }^{21}$.

So far, cefotaxime and ceftriaxone are the drugs of choice, though some failures in this treatment have suggested the inclusion of vancomycin. This is the current recommendation for antimicrobial treatment, mainly in areas where there is a prevalence of highly-resistant Pneumococcus.

Though diminished sensitiveness to cephalosporin has not been reported in vitro in Cuba, the unfavorable in vivo response to these antibiotics was quite important to take into account regarding this decision ${ }^{22}$. The most frequent antibiotics used were rocephin (ceftriaxone) and vancomycin.

Since there have been no isolation of vancomycin-resistant strains, this is the drug of first choice, combined with a cephalosporin either cefotaxime or ceftriaxone to manage meningitis caused by third- generation- cephalosporin- resistant pneumococci. Similar to cephalosporin and carbapenem, the effectiveness of vancomycin is based on the percentage of time in which its concentration in CSF surpasses the minimum bactericide concentration, so the administration intervals are more frequent, form 6 to 12 hours $^{23}$.

The recent report of Streptococcus pneumoniae tolerant to vancomycin, there has been a demand to be alert and to make a rational use of this antibiotic ${ }^{24}$.

The impact of the introduction of this antibiotic will not replace the early clinical diagnosis of bacterial meningitis at initial stages of inflammatory response, and the time for adopting measures to improve hemodynamic conditions.

Computed tomography was performed in patients with cerebral paralysis. In developing countries, access to these diagnostic techniques is important for early detection of the sequels of the disease because image findings correlate statistically with neurological signs ${ }^{25}$.

In a study carried out in India, sequels were observed in $40 \%$ of patients with meningoencephalitis, $10 \%$ with minor sequels, while the remaining presented more severe sequels. Sequels were observed in neurodevelopment, in cranial paralysis, convulsions and deep hyporeflexia ${ }^{26}$.

The usefulness of computed tomography to foretell sequels was demonstrated in a study carried out by Tuncer et al. ${ }^{27}$.

As previously explained, patients with this disease are in very serious condition, thus the early treatment of brain edema is important to reduce mortality.

In conclusion, patients with Streptococcus pneumoniae meningoencephalitis presented clinical characteristics, 
complications, and sequels which were different to other bacterial meningoencephalitis, this being a motive to help physicians in the differential diagnosis.

\section{REFERENCES}

1. Ruvinski RO. Streptococcus pneumoniae: epidemiología y resistencia a antimicrobianos de las enfermedades invasoras en Latinoamérica. Rev Chil Infectol 2001;18:45-48.

2. Advisory Committee on Immunization Practices (ACIP): Recommendations of the ACIP. MMWR 1997:46.

3. Dickinson F, Pérez A, Galindo MA, Quintana I. Impacto de la vacunación contra Haemophilus influenzae tipo b en Cuba. Rev Panam Salud Pública 2001;34:169-174.

4. Nicolosi L, Langella L, Krzysztofiak A, Ticca F. Streptococcus pneumoniae meningitis in children: case records 1985-2003. Infect Med 2004; 12 : 252-258.

5. Baudner S, Bienvenu J, Blirup JS, et al. The certification of a matriz reference material for immunochemical measurement of 14 human serum proteins. CMR 470. Brussels: Community Bureau of Reference, Commission of the European Communities. BCR Information, Reference Materials. (report UR 15243); 1993.

6. Vlug A,van Remortel A. The structure and function of human IGg subclases. Eur Clin Lab 1989;8:26-35.

7. Viswanath G, Praveen M, Hanumanthappa AR, Chandrappa NR, Mahesh CB. Bacteriological study of pyogenic meningitis with special reference to latex agglutination. Indian J Pathol Microbiol 2007;50:97-100.

8. Singhi S. Fluid restriction and intracraneal pressure during bacterial meningitis: to restrict fluid or not. (Abstract). $10^{\text {th }}$ International Congress on Infectious Diseases. Singapore; 2002:130.

9. Otero MC, Pérez D, Asensi F. Meningitis bacterianas. In: Protocolos diagnósticos y terapéuticos en Pediatría. Tomo 2. Infectología. Madrid: Asociación Española de Pediatría; 2001:149-155.

10. Brockmann VP, Ibarra GX, Silva WI, Hirsch BT. Etiología de la fiebre aguda sin causa en niños consultados en un departamento de emergencia. Rev Chilena Infectol 2007:24:33-39.

11. Tique V, Alvis N, Parodi R, Bustos A, Mattar S. Meningitis aguda en Córdoba, Colombia (2002-2004). Rev Salud Pública (Bogotá) 2006;8:33-46.

12. Guarner J, Packard MM, Nolte KB, et al. Usefulness of immunohistochemical diagnosis of Streptococcus pneumoniae in formalin-fixed, paraffin-embedded specimens compared with culture and gram stain techniques. Am J Clin Pathol 2007;127:612-618.
13. Bernaola E, Aristegui J de M. Estudio de la incidencia de enfermedad neumocócica invasora entre 0-5 años en el País Vasco y Navarra. An Esp Pediatr 2002;57:301-309.

14. Benítez Bermejo RI, García Deltoro M, Vicente Mas J, Ballester Belda JE. Lesiones cerebrales en pacientes diagnosticados con meningitis. Neurología 2006;21:34-36

15. Tuncer $\mathrm{O}$, Caksen H, Arslan S, et al. Cranial computed tomography in purulent meningitis of childhood. Int J Neurosci 2004;114:167-174.

16. Kertesz DA, Di Fabio JL, Brandileone MCC, et al. Invasive Streptococcus pneumoniae infection in Latin American children: results of the Pan American Health Organization Surveillance Study. Clin Infect Dis 1998;26:1355-1361.

17. Barboza AG, Ioli PL, Zamarbide I, Estragó MI, Castiñeiras F, Wouters L. Estudio de incidencia y análisis descriptivo de la meningitis bacteriana primaria no tuberculosa del adulto en una población argentina. Rev Neurol 2002;35:508-512

18. Noris García E, Dorta Contreras A, Noris García J L. Evaluación inmunológica y tratamiento en pacientes pediátricos con déficit de IgA.Alergol Inmunol Clin 2002;17:180-184.

19. Desse JE. Meningitis bacteriana: avances en el diagnóstico y tratamiento. II Congreso Virtual Iberoamericano de Neurología, 1999.

20. Alvez F. Meningitis bacteriana. In: Castro Gago M (Ed). Tratamiento de las enfermedades neurológicas en niños y adolescents. Barcelona: Ed Espaxs 1999;2:119-125.

21. Goldwater PN. Cefotaxime and ceftriaxone cerebrospinal fluid levels during treatment of bacterial meningitis in children.Int J Antimicrob Agents 2005;26:408-411.

22. Luján Padrón A, Hernández Hernández R. Neumococo. resistencia bacteriana a los antibióticos. Rev Cubana Med Gen Integr 2001;17:23-26.

23. Rodriguez CA, Atkinson R, Bitar W, et al. Tolerance to vancomycin in pneumococci: detection with a molecular marker and assessment of clinical impact.J Infect Dis 2004;190:1481-1487.

24. Suntur BM, Yurtseven T, Sipahi OR, Buke C, Buke M. Rifampicin+ ceftriaxone versus vancomycin+ceftriaxone in the treatment of penicillinand cephalosporin-resistant pneumococcal meningitis in an experimental rabbit model. Int J Antimicrob Agents 2005;26:258-260.

25. Dorta Contreras AJ, Núñez Fernández FA, Pérez Martín O, et al. Peculiaridades de la meningoencefalitis por Angiostrongylus cantonensis en América. Rev Neurol 2007;45:755-763.

26. Singhi P, Bansal A, Geeta P, Singhi S. Predictors of long term neurological outcome in bacterial meningitis. Indian J Pediatr 2007;74:369-374.

27. Tuncer $\mathrm{O}$, Caksen H, Arslan S, et al. Cranial computed tomography in purulent meningitis of childhood. Int J Neurosci 2004;114:167-174. 